\title{
MULTICULTURAL COMPETENCE AWARENESS AMONG INTERNATIONAL STUDENTS IN YOGYAKARTA STATE UNIVERSITY
}

\author{
Edith Romano Galindo ${ }^{1 *}$; Erna Andriyanti ${ }^{2}$ \\ 1,2 Department of Applied Linguistics, Languages and Arts Faculty, Yogyakarta State University \\ Jl. Colombo Yogyakarta No. 1, Karang Malang, Sleman, Daerah Istimewa Yogyakarta 55281, Indonesia \\ 'edithromaga@gmail.com; ${ }^{2}$ erna.andriyanti@uny.ac.id
}

Received: $19^{\text {th }}$ January 2021/ Revised: $30^{\text {th }}$ March 2021/ Accepted: $30^{\text {th }}$ March 2021

How to Cite: Galindo, E. R. \& Andriyanti, E. (2021). Multicultural competence awareness among international students in Yogyakarta State University. Humaniora, 12(2), 119-126. https://doi.org/10.21512/humaniora.v12i2.6949

\begin{abstract}
The research aimed to describe and interpret the characteristics of multicultural awareness of seven international students studying tertiary education in the postgraduate studies department at Yogyakarta State University. When individuals moved to a place where more than one culture coexists, they were now part of a multicultural society. In this respect, one of the many reasons for the existence of multicultural societies was the student mobility phenomenon in which many students decided to live abroad to pursue their academic goals. Accordingly, these students faced new cultural situations, and there was no doubt that they needed to use their multicultural competencies. However, were they aware of their own multicultural competence? Had the way they conceptualized it ever helped them to achieve their professional goals? In the research, such questions highlighted the relevance of focusing on the existing knowledge about multicultural competence of international students, which might provide insights into the role of multicultural competence as an inherent aspect of life to achieve personal or professional goals and strengthen their intercultural communication. Many pieces of research have already focused on the teachers' multicultural competence and the importance of incorporating it in the programs. However, not many of them focused on the way students conceptualized it and perceived it in their lives. By using qualitative research and making use of a questionnaire as the main instrument, the findings show that students have a high level of awareness, and they mostly conceive it as a tool to achieve their professional goals.
\end{abstract}

Keywords: culture, multicultural competence, international students, intercultural communication

\section{INTRODUCTION}

Nowadays, it is important to look at multicultural competence because there are more people whose goals are to migrate, work, or study abroad. This means they will be part of a culture very different from them. Needless to say that it is even more common to find countries that are becoming more ethnically and racially diverse since many cultures converge and interact together. Consequently, people need the ability to conceive, understand, and adapt to more than one new culture in order for them to achieve their personal or professional objectives.

Usually, cultural competence is highly important in healthcare, counseling, nursing, social work, human services, and some other areas. For instance, in nursing, articles about critical care nurses hold that cultural competence can help nurses create better understanding with their patients. Improved levels of communication can be a serious factor in assessing patient needs and developing suitable treatments and interventions (Flowers, 2004). In the same way, in the field of international social work, Nadan (2017) has claimed that cultural competence is essential and a key concept for implementing multicultural ideology in professional practice that deals with domestic diversity and its implications for social work at microand macro-levels.

In brief, the emphasis on the importance of cultural competence in many areas of society can be noticed. In such organizations, people even plan training and mentoring courses for the development of their employees' cultural competence because it is clear that developing this skill improves understanding 
among cultures and benefits many people. Then, it is for this reason that it becomes relevant to talk about the importance of cultural competence in education too, since, for instance, factors like the fear of diversity and the resistance to dealing with race and racism are still frequently expressed by students enrolled in teacher education programs (Gay \& Howard, 2000).

Nowadays, many scholars have claimed that diversity is one characteristic of $21^{\text {st-century }}$ society. Therefore, diversity in schools is not the exception. In the opinion of Pang et al. (2011), it is indispensable for educators to develop cultural skills because, in this way, they can reach all students. Thus, they claim that educators with multicultural skills can create across-cultural bridges because they can identify and use cultural contexts in their instructional interactions with students (Gallavan, 2000; King, Sims, \& Osher, 2000, as cited in Pang et al., 2011). Moreover, they add that for many culturally varied students, cultural competencies in teachers are important elements in ensuring that children and adolescents have equal chances to learn. Along with this, Lindsey et al., as cited in Trumbull \& Pacheco (2005), have stated that the first step for teachers in developing cultural competencies is recognizing how their own perspectives and knowledge of the world are entrenched in a particular cultural, racial, ethnic identity, and history. In this respect, studies have been made in order to describe the level of multicultural competence in the teachers. For instance, the research of Vincent and Torres (2015) aims to describe the level of multicultural competence among secondary agriculture teachers having a minimum of $30 \%$ ethnic student's matriculation. Then, it shows that teachers who surround themselves with culturally different students express a greater sense of multicultural competence and are aware, knowledgeable, and have more skills when interacting with students of different cultures. Moreover, the findings from the students' perception claim that students can identify a teacher who is and is not multicultural competent. According to the research, it is suggested to provide preservice teachers with immersion exercise and clinical hours in ethnically diverse classrooms in order to find approaches that raise secondary agriculture teachers' multicultural competence.

Similarly, Lehman's research (2017) has found that preservice teachers perceived a necessity for additional multicultural competence, including amplified awareness, knowledge, and skills in working with various students. Thus, the research highlights the need to strengthen preservice teacher multicultural competence in order to bring it into the teacher preparation programs. Along with these lines, Džalalova and Raud (2012) have stated in their research that multicultural competence is considered a key component of professional teacher education because it contributes to the development of cognition, personality, and professional activities. Thus, their research claims that teacher education programs should give students opportunities to apply knowledge on multicultural or plurilingual aspects by conducting research activities in both areas.

Accordingly, educators are an essential element. Many pieces of research focus on the teachers' multicultural competence and the fact that it must be implemented in each one of the education levels. Similarly, in some other research, it has been recognized the importance of putting multicultural competence into practice in the student affairs administration because, in this way, they will be able to address and respond to the challenges and requirements of different student populations (Major \& Mangope, 2014). However, this means that once again, the focus is on the person in charge to foster multicultural competence and not on how it is already perceived or carried out by the students. Thus, since multicultural competence awareness, knowledge and skills are essential to building multicultural campuses (Pope \& Mueller, 2005), this research focuses on awareness because it can be said that it is the first step to become multicultural competent. According to Iverson (2012), awareness is openness to learning about differences associated with various cultures and being conscious of biases and assumptions and their impact on others. Similarly, Mio, Barker-Hackett, and Tumambing (2012) have pointed out that multicultural skill includes increasing awareness of one's own cultural values and preconceptions, learning to value others' worldviews, and developing a set of culturally suitable interpersonal skills.

Thus, the research paying attention to the students' existing knowledge of multicultural competence and the way they perceive it in their everyday lives is crucial. More specifically, the research focuses on foreign students living in a different country from theirs in order to pursue their academic goals. Student mobility is a worldwide phenomenon in which every year many students make the decision to study abroad, and when they move, they bring with themselves their own culture to interact with a new one. Nevertheless, are the students aware of their own multicultural competence? If so, are they able to identify it in their everyday life?

The hypothesis is that students assume the importance of multicultural competence but are unaware that it is an inherent process in their lives, perceiving it mainly as an independent skill that can be applied in specific situations. From the researchers' point of view, this idea is a sample of how people perceive multiculturalism worldwide. It is believed that even though the definition of culture has been studied for a long time and with it keywords such as diversity, tolerance, ways of life, etcetera have been developed, giving as a result more specific terms like interculturality, it seems to be that many conflicts and harms of cultural rights continue existing in many parts of the globe.

Thus, before the researchers intend to approach the role of multicultural competence at a macro level, this research aims to understand the conception at the individual level first. In other words, it is clear 
that multiculturalism has become a common term in societies in recent years; thus, it is believed that individuals are at some level familiarized with the term. Hence, according to their background knowledge, countries, and experiences, they have conceptualized a notion of what it would mean to be multiculturally competent, especially within the context of student mobility.

Therefore, the purpose of the research is not to measure the degree of multicultural competence but to explore and describe the characteristics of multicultural competence awareness of international students from different countries who chose to study their tertiary education in Indonesia. The collected data is going to help to understand the student's perception and awareness of their multicultural competence in relation to their academic context to determine whether or not they are able to identify it and to find out whether or not multicultural competence have let them achieve their personal and professional goals according to them.

The research applies a qualitative research that give a sample of relevant insights about what is commonly understood as multicultural competence in this current time. Moreover, the most important benefit of the research emphasizes understanding and carrying out multicultural competence effectively. It is important to understand first how meaningful and ubiquitous it is in the individual state and everyday social interactions. It strongly supports this idea. Thus, given that just a little information is available on students' multicultural awareness, the research results will add more information to future studies about multicultural competence.

Consequently, it is important to have clear what culture and cultural competence are. For example, every time the word culture has been mentioned, those elements of society, such as traditions, festivals, and literature, come to others' minds. However, this term has been widely reflected, and it embraces more aspects than the ones mentioned before. Moreover, it has been studied from the perspective of various areas such as anthropology, sociology, and psychology.

According to sociological point of view, Lustig and Koester, as cited in Moloi and Bam (2014), have stated that culture is shared understandings about beliefs, values, norms, and social practices, which affect the conduct of a relatively large group of people. Similarly, in the opinion of Giddens and Sutton (2009), culture refers to the ways of life of the members of society, or of groups within a society which includes how they dress, social customs, language and family life, their patterns of work, religious ceremonies, and leisure recreations. In the same way, one more definition is given by Gunawardena (2012), who holds that culture is created and shared by individuals of a specific group varying from ethnic and national groups that integrates an organism of knowledge, experiences, behaviors, customs, and believes. In sum, these three definitions emphasize the relevance of the construction of shared knowledge, and as it can be noted, it is very significant because it configures their way of living, the way they look at themselves, the past, present, and future as being part of a determined community of people.

Culture is fundamental to learning processes and environments (Colbert, 2010). That is why every person is immersed in culture at every moment, consciously or unconsciously. As Kivel (2007) has noted, people are all culturally competent in their own culture. They know the language, nuances, and assumptions about how the world is defined and organized. This means that this process takes into account the internal and external interactions people experience during life individually and collectively.

Then, it can be implied that the cultural competence concept must consider the ability to think, feel, and act in ways that acknowledge, respect, and build upon ethnic, sociocultural, and linguistic diversity. Moreover, it also includes the awareness, knowledge, and skills needed to work with others who are culturally different in order for individuals to gain broadening perspectives on the simultaneous existence of diverse realities that require comparison, judgments, awareness of cultural miscommunication, and others. Likewise, Olsen et al., as cited in Moloi and Bam (2014), has defined cultural competence as the ability to work effectively across cultures and as an approach to learning, communicating, and working respectfully with people from cultures different from one's own.

Along with this, the National Center for Benefits Outreach and Enrollment (NCOA - National Council on Aging, 2011) has held that cultural competence includes the elements of understanding and valuing diversity. Self-assessment means being able to look judgmentally at one's own culture and how these influences perceptions of others. The consciousness of differences, i.e., understanding how the varying elements of culture come into play in human interactions; institutionalization of cultural knowledge, which is the ability to acquire knowledge about other cultures and use that knowledge at an operational level within an organization. Finally, adaptation is seen as the capacity to adjust to diversity and the varying context of communities.

Because of that, Chen and Starosta, as cited in Altan (2018), have highlighted another idea associated with cultural competence: intercultural sensitivity, which they define as the emotional aspect of intercultural communication where the individuals have an active desire to motivate themselves to understand, appreciate, and accept differences among cultures. This is highly related to the consciousness of differences that is previously stated by NCOA. However, in this definition is not only important to identify and understand how the differences work but also to include the intrinsic motivation the individual may have to make him willing to agree, accept, and understand these differences. Accordingly, this is an essential element because it may determine to what extent the individual is willing to continue interacting 
with the new culture. Interaction is a key point that is why cultural competence could also be coined as intercultural competence.

Thus, in other words, an individual can feel culturally competent as a result of learning the customs and traditions of different cultures and communicating more respectfully and appropriately with members of different cultures (Olsen et al., as cited in Moloi \& Bam, 2014). Kivel (2007) has also commented that learning to be sensitive to the cultural expressions of another group is not hard but does require time and energy to learn to observe, empathize, and increase in value other people's ways of doing things to come to be culturally competent.

All in all, it can be seen that cultural competence definitively works at the individual level with one's own culture, then it continues until there is interaction with another one. This process is repeated as many times as cultures are immersed. In this respect, multicultural competence makes people appreciate the concept of 'multiculturalism'. According to Yilmaz (2016), this concept emphasizes the regional linguistic and cultural union that involves the idea of human rights and equal civil rights. Moreover, it emerges from the concept of the coexistence of nations with different languages, nationalities, geography, religion, etcetera. It is important to note that there are also the terms pluriculturalism and interculturalism. In this respect, the Council of Europe (Huber, 2012) states that while multiculturalism emphasizes the presence of various groups in a community, pluriculturalism refers to the integration of aspects of other cultures by the individual. On the other hand, interculturalism refers to the active dimension of diversity, which assumes the interaction of individuals, groups, and communities and their capacity to build mutual projects, accept shared responsibilities, and generate common identities.

All of these terms are linked. They include those situations where individuals need to put into practice their cultural awareness, knowledge, and skills to be able to understand and adapt in those settings at the individual and collective levels. In these instances, one important aspect that cannot be left behind is the role of language that leads to account for the importance of multicultural competence in intercultural communication. This fact makes people focus on contexts where multilingualism takes place. In the opinion of Clyne (2017), a common definition of multilingualism would be the use of more than one language or competence in more than one language. This competence refers to the linguistic repertoire of language competencies an individual has also coined as plurilingualism (Huber, 2012). Similarly, Franceschini (as cited in Pütz \& Mundt, 2018) has defined it as the capacity of societies, institutions, groups, and individuals to engage regularly in space and time with more than one language in everyday life.

From all the mentioned, it can be implied that multilingualism is a vital element within multicultural competence and contributes to achieving intercultural communication. In the existing records about intercultural communication, many definitions have been given. For example, Gudykunts (as cited in Arasaratnam \& Doerfel, 2005) has defined it as the communication between people from different national cultures. On the other hand, in the opinion of Garcia (2013), some definitions emphasize the specific moment in which the ability to negotiate cultural meanings in communicative interaction becomes apparent. Some others broaden the concept by going beyond the geographical area, including, for example, dimensions such as social class, age, gender, ideology, and sexual preference, to name a few.

Then, intercultural communication is actually a mechanism of meaning mutual creation among cultures. This means that intercultural communication is a deeper and wide interaction that takes into account a worldwide point of view and is able to generate common knowledge, understanding or ideologies, among cultures without stopping perceiving their differences. Some authors use interchangeably the terms multicultural competence and intercultural competence.

In sum, cultural competence, multicultural competence, and intercultural competence form part of a continuum that starts from individuality and continues collectively in people's life. Thus, it can be implied that cultural competence is inherent as well as shaped by peoples' experiences. One of these experiences is international student mobility.

The idea of international education is essential that is widely assumed. It is a result of economic globalization and the heightening of governments' awareness of the perceived links between education and economic competitiveness (UNESCO, 2013). According to the Organization for Economic Co-operation and Development (OECD, 2021), international students receive their prior education in another country and are not residents of their current country of study. The number of overseas students enrolled in tertiary education around the world has risen meaningfully. According to the OECD (2013), nearly 4,3 million students are enrolled in universitylevel education outside their home country. Australia, the United Kingdom, Switzerland, New Zealand, and Austria have, in descending order, the highest percentage of international students". International student flows are affected by a diversity of domestic factors. An example is the limited availability of places for resident students in local higher education institutions or those serving to invite foreign students to study in a particular country (UNESCO, 2013).

Thus, living day by day in a foreign country is an enriching experience that undoubtedly influences students' personal and professional development. This experience allows them to learn the culture, customs, and, often, the language of the host country. In addition, they must be able to adapt to another way of life, to other schedules, opinions, and thoughts; it requires an open personality and a tolerant character, attitudes that are learned by living and studying with 
people from other countries.

Social science studies have shown that international experiences can improve creativity, reduce bias between groups, and promote professional success. According to Adam et al. (2018), selfconcept conception is the extent to which a person's understanding of himself is clearly defined and with confidence, internally consistent, and temporarily stable. They have found in six studies with 1.874 participants that living abroad leads to a better knowledge of self-concept. Consequently, they are not only able to develop the self-concept conception but the multicultural competence, which is broader. In the opinion of the ASEAN University Network (2017), when students are exposed to different cultures and social contexts, they are also encouraged to respect the norms and values of the country they visit. They have to understand and comply with the local regulations and laws. This means that it is important for them to be culturally competent so that they can raise their cultural knowledge and face the possible situations of miscommunication or adaptation difficulties. In some situations, such difficulties would lead students to quit their academic goals. Moreover, as Kivel (2007) has claimed to be culturally competent, people have a broader, richer, and more accurate view of the world because they can work together as full and equal partners.

\section{METHODS}

The research aims to describe and interpret the characteristics of multicultural awareness of seven international students at the postgraduate studies department at Yogyakarta State University (YSU). Thus, to achieve such an objective, a qualitative research is appropriate because, as Denzin and Lincoln (2005 as cited in Aspers \& Corte, 2019) claim, a qualitative research studies and interprets phenomena in terms of the meanings people convey and bring to them. In other words, a qualitative research is helpful to find out how people feel or what they think about a particular subject. Therefore, the scope of the research is the interpretation of the way international students perceive and conceptualize their own multicultural competence while living abroad. In this respect, grounded theory is mainly used since the data are systematically collected and analyzed based on a theoretical framework.

The participants are seven international students from different countries: Turkmenistan, China, Ghana, Vietnam, Rwanda, Tanzania, and the Philippines. The participants from Turkmenistan and China have already completed their master's degree, the participant from Ghana is studying for a doctoral degree, while the participants from Vietnam, Rwanda, Tanzania, and the Philippines study master's degrees in the third and first semesters. Their ages range from 22 to 46 years old. They all have been in Indonesia for more than one year.
For the purpose of the research, a questionnaire is designed to collect the data about the students' awareness of multicultural competence. The questionnaire is presented in two parts. In the first section, they answer three open-ended questions concerning how important multicultural competence is for them, and this section is applied together with an indepth interview. The second part of the questionnaire is a Likert scale table with eight statements written in the first person of the singular relating to the elements of cultural competence presented in the literature review. Accordingly, these statements find out whether or not they can identify the elements of cultural competence in their lives. In this part, participants need to answer whether they agree, disagree, or are uncertain about the statements. Statements 1 and 3 reflect the general element of understanding and valuing diversity; statements 2 and 4 relate to self-assessment; statement 5 is about the consciousness of differences; statement 6 relates to institutionalization of cultural knowledge; statement 7 is about adaptation; and statement 8 has to do with intercultural sensitivity. Table 1 shows cultural competence elements Likert scale based on Chen and Sarosta (1998), Olsen et al. (in Moloi \& Bam, 2014), Kivel (2007), and NCOA (2011).

\section{Table 1 Cultural Competence Elements Likert Scale}

1. I have the ability to acknowledge, respect, and develop ethnic, sociocultural, and linguistic diversity in my culture and others.

I agree Uncertain Disagree

2. I consider myself able to have the knowledge, and skills needed to work with others who are culturally different from my culture.

I agree Uncertain Disagree

3. I am able to understand and value diversity.

I agree Uncertain Disagree

4. I am able to look critically at my own culture and how this influences perceptions of others.

I agree Uncertain Disagree

5. I am able to understand how the varying elements of culture come into play in human interactions.
I agree
Uncertain
Disagree

6. I have the ability to acquire knowledge about other cultures and use that knowledge at an operational level within an organization.

I agree Uncertain Disagree

7. I have the ability to adapt to diversity and the changing context of communities.
I agree
Uncertain
Disagree

8. I have an active desire to motivate myself to understand, appreciate, and accept differences among cultures.

I agree Uncertain Disagree

First, to collect the data for the research, a questionnaire and an in-depth interview are designed. 
It is important to mention that both instruments are necessary in order to ensure credibility, which is the equivalent of internal validity in quantitative research and is concerned with truth-value (Korstjens \& Moser, 2018). Thus in the research, the questionnaire obtains relevant information about what participants know about cultural competence. On the other hand, the in-depth interview lets the researcher have profound opportunities to obtain more and rich information by using follow-up questions and recovery key questions during the session. Secondly, students are asked to participate in the project by answering the written questionnaire and an in-depth interview. Subsequently, it proceeds with analyzing and interpreting the data from the written Likert scale questionnaire and the indepth interview.

\section{RESULTS AND DISCUSSIONS}

In this section, a detailed description and a discussion of the participants' responses to the indepth interview and the Likert scale questionnaire are presented. The first question is, "Do you consider necessary to develop multicultural competence? If yes, why?" Students are asked whether or not they considered a need to develop multicultural competence and, if yes, to explain why. Accordingly, the seven students answer 'yes'. They claim that the importance of multicultural competence relies on the fact that it fosters respect and understanding with other cultures, which in turn lets them interact with other people. Besides, some of them identify it as 'the key of success' as well as a vital skill in the $21^{\text {st }}$ century, highlighting the fact that companies and organizations look for multicultural competent people. This statement is actually congruent in the physical and health fields; according to Tritschler (2008), cultural competence is a requisite for all $21^{\text {st }}$-century activity physical leaders.

The purpose of the question "Do you consider yourself multicultural competent? If yes, why?" is to find out how they perceive themselves in multicultural contexts. Accordingly, all the participants consider themselves multicultural competent. It can be observed in the participants' responses in answering the question. They need to recall experiences or situations they go through in multicultural contexts. For instance, in the opinion of the participants, the interaction they have within the cultures in their own country, their friends from different cultures, trips to other countries, and the extent of immersion they have had in other people's cultures make them culturally competent.

Moreover, they highlight the importance of being respectful to have harmonious relationships, being open-minded to understand the differences among cultures, and being tolerant and able to speak the local language at least at the basic level. As a result, they consider it 'life skills', and the fact that they look at themselves as multicultural competent makes them feel like they are in their country of origin.

The third question, "Do you consider multicultural competence has helped you achieve professional or personal goals? If yes, could you please explain why?" is considered to find out whether or not they can identify the correlation between cultural competence and their goals in life. That is to say, participants are asked to explain if they see a direct relation of multicultural competence with their achievements in life. The participants' answer is 'yes'. In general, they reflect that multicultural competence has helped them understand the background knowledge and people, solve a problem, and be able to tolerate and live in diversity. For instance, in their professional career, this competence is useful to be able to continue studying for their master's degree. In their personal life, the impact of this competence relies on the construction of solid friendships.

On the other hand, according to the participants' responses to the Likert scale questionnaire, they seem to be able to identify the elements of cultural competence because they agree with most of the statements. Participant 1 agrees on five of the eight statements. She remains uncertain in the statements related to understanding and valuing diversity, the consciousness of differences, and adaptation. Participant 2 agrees on seven of the statements and is uncertain in only one that relates to the institutionalization of cultural knowledge. Participant 3 agrees on all of the statements. Participant 4 agrees on most of the statements but is uncertain on the element of institutionalization of cultural knowledge. Participants 5, 6, and 7 agree with all the statements.

In Table 2, the research presents the results in terms of percentage. It can be seen the six general elements of multicultural competence taken from Chen and Sarosta (1998), Olsen et al. (2006, in Moloi \& Bam, 2014), Kivel (2007), and NCOA (2011) presented in the theoretical framework. Therefore, from Table 2, it can be observed that participants agree $96 \%$ on the statements regarding the understanding and valuing diversity, $100 \%$ of the agreement to those statements of self-assessment, and intercultural sensitivity. Participants agree $86 \%$ on the statements relating to the consciousness of differences and adaptation. Finally, they agree $71 \%$ on the statement related to institutionalization of cultural knowledge.

In the research, the high level of agreement shows that participants are familiar with the elements of multicultural competence; for this reason, they can identify them in their lives. It can be implied that when they are uncertain, it means that they do not too understand what the statement refers to or have not experienced those instances yet.

Accordingly, the research aims to describe and interpret the characteristics of multicultural competence awareness of seven international students who study master's degree and doctoral studies in Indonesia. The results show that students have a high level of awareness because their responses contain much of what the scholars say that cultural competence is. Overall, the student's conception of multicultural competence holds that it is necessary 
to develop cultural competence because it fosters respect and understanding with other cultures and, in turn, to be able to interact with other people. For this reason, what makes them culturally competent are their experiences, the interactions they have had with the ethnic groups in their own country and with their friends from different countries, their trips abroad and the extent of immersion they have had in other people's cultures as well as their linguistic ability.

Moreover, they consider multicultural competence as helpful to achieve some of their personal and professional objectives because it has helped them understand the background knowledge of the country they live in and the people they interact with, to solve any communicative problem. In addition, according to them, it is useful to be able to tolerate and live-in diversity.

From all the evidences, it means that they are able to identify the elements of cultural competence in their everyday life because they seem to have already experienced situations where they have put into practice multicultural competence. That is why they agree with most of the statements concerning the elements of cultural competence.

Table 2 Results of the Analysis of the Cultural Competence Likert Scale

\begin{tabular}{lccc}
\hline & Agree & Uncertain & Disagree \\
\hline $\begin{array}{l}\text { Understanding and } \\
\text { valuing diversity }\end{array}$ & $96 \%$ & $4 \%$ & $0 \%$ \\
$\begin{array}{l}\text { Self-assessment } \\
\begin{array}{l}\text { Consciousness of } \\
\text { differences }\end{array}\end{array}$ & $100 \%$ & $0 \%$ & $0 \%$ \\
$\begin{array}{l}\text { Institutionalization } \\
\text { of cultural }\end{array}$ & $71 \%$ & $29 \%$ & $0 \%$ \\
knowledge & & $14 \%$ & $0 \%$ \\
$\begin{array}{l}\text { Adaptation } \\
\begin{array}{l}\text { Intercultural } \\
\text { sensitivity }\end{array}\end{array}$ & $86 \%$ & $14 \%$ & $0 \%$ \\
\hline
\end{tabular}

\section{CONCLUSIONS}

Based on the research's results, it cannot be confirmed the research's hypothesis. According to the research, students do not consider multicultural competence as an independent skill; on the other way around, they do consider it as an inherent aspect of their lives. They recognized it as a tool or a medium that they have put into practice since childhood in their countries. For this reason, when they are abroad, they know what it is necessary to do when interacting with more cultures. In this sense, it can be implied that international students do perceive cultural competence as ubiquitous property of people's lives, and they agree on the general concept even though they come from different countries.

Thus, the main finding of the research is that the common conception of multicultural competence of international students is characterized by three elements: their experiences, interactions based on respect with other cultures, and the perception of usefulness, which is the most persistent element in the responses of the participants. For this reason, the 'perception of usefulness' is actually a new element for further research on the area in order to know to what extent the 'perception of usefulness' of the competence is related to improving this ability. Moreover, it is also suggested to focus on those international students who decided to quit their academic programs abroad to figure out whether or not there is any direct correlation between multicultural competencies and the achievement or failure of academic goals. Finally, it is important to mention that the main limitation of the research is the small number of participants. That is why the researchers cannot generalize the results to the broader context.

\section{REFERENCES}

Adam, H., Obudaru, O., Lu, J., Maddux, W., \& Galinsky, A. (2018). How living abroad helps you develop a clearer sense of self. Retrieved from https://hbr. org/2018/05/how-living-abroad-helps-you-developa-clearer-sense-of-self.

Altan, M. Z. (2018). Intercultural sensitivity: A study of pre-service English language teachers. Journal of Intercultural Communication, 46, 1-17.

Arasaratnam, L. A., \& Doerfel, M. L. (2005). Intercultural communication competence: Identifying key components from multicultural perspectives. International Journal of Intercultural Relations, 29(2), 137-163. https://doi.org/10.1016/j. ijintrel.2004.04.001.

Aspers, P., \& Corte, U. (2019). What is qualitative in qualitative research. Qualitative Sociology Journal, 42(2), 139-160. https://doi.org/10.1007/s11133-0199413-7.

Asean University Newtwork. (2017). Crisis management: Framework for international student mobility. Retrieved from http://www.aunsec.org/Final\%20 AUN\%20Crisis\%20Managment01.pdf.

Chen, G. M., \& Starosta, W. J. (1998). A review of the concept of intercultural awareness. Human Communication, 2, 27-54.

Clyne, M. (2017). Multilingualism. In The Handbook of Sociolinguistics (pp. 301-314). New Jersey: John Wiley \& Sons, Ltd. https://doi. org/10.1002/9781405166256.ch18.

Colbert, P. J. (2010). Developing a culturally responsive classroom collaborative of faculty, students, and institution. Journal of College Teaching \& Learning (TLC), 7(11), 15-24. https://doi.org/10.19030/tlc. v7i11.247.

Džalalova, A., \& Raud, N. (2012). Multicultural competence and its developement in students of teacher education curricula. Problems of Education in the $21^{\text {st }}$ Century Journal, 40, 65-74. 
Flowers, D. L. (2004). Culturally competent nursing care. Critical Care Nurse, 24(4), 48-52. https://doi. org/10.4037/ccn2004.24.4.48.

García, M. R. (2013). Comunicacion e interculturalidad: Reflexiones en torno a una relacion indisoluble. Global Media Journal Mexico, 10(19), 26-42.

Gay, G., \& Howard, T. C. (2000). Multicultural teacher education for the $21 \mathrm{st}$ century. The Teacher Educator Journal, 36(1), 1-16. https://doi. org/10.1080/08878730009555246.

Giddens, A., \& Sutton, P. W. (2009). Sociology. Cambridge: Polity Press.

Gunawardena, C. N. (2012). Culture and online distance learning. UK: Routledge Handbooks Online. https:// doi.org/10.4324/9780203803738.ch12.

Huber, J. (Ed.). (2012). Intercultural competence for all: Preparation for living in a heterogeneous world. France: Council of Europe Publication.

Iverson, S. V. (2012). Multicultural competence for doing social justice: Expanding our awareness, knowledge, and skills. Journal of Critical Thought and Praxis, 1(1), 62-87. http://dx.doi.org/10.31274/ jetp-180810-14.

Kivel, P. (2007). Multicultural competence. Retrieved from http://paulkivel.com/resource/multiculturalcompetence/.

Korstjens, I., \& Moser, A. (2018). Series: Practical guidance to qualitative research, part 4: Trustworthiness and publishing. European Journal of General Practice, 24(1), 120-124. https://doi.org/10.1080/13814788.2 017.1375092 .

Lehman, C. L. (2017). Multicultural competence: A literature review supporting focused training for preservice teachers teaching diverse students. Journal of Education and Practice, 8(10), 109-116.

Major, T. E., \& Mangope, B. (2014). Multicultural competence in student affairs: The case of the University of Botswana. Journal of Student Affairs in Africa, 2(1), 23-33. https://doi.org/10.14426/jsaa. v2i1.58.

Mio, J. S., Barker, L. A., \& Tumambing, J. S. (2012). Multicultural psychology: Understanding our diverse communities. Oxfrod: Oxford University Press.

Moloi, C., \& Bam, M. (2014). Exploring cultural competence from a sociological point of view. Mediterranean Journal of Social Sciences, 5(3), 332-337. http:// dx.doi.org/10.5901/mjss.2014.v5n3p332.

Nadan, Y. (2017). Rethinking 'cultural competence' in international social work. Journal of International Social Work, 60(1), 74-83. https://doi. org/10.1177/0020872814539986.
NCOA (National Council on Aging). (2011, November). Cultural competence \& benefits access. Retrieved from https://www.ncoa.org/resources/culturalcompetence-benefits-access/.

OECD (Economic Co-operation and Development). (2013). How many students study abroad and where do they go? Education at a Glance 2013 Highlights, 32-35. https://doi.org/10.1787/eag highlights-2013-12-en.

OECD (Economic Co-operation and Development). (2021). Students - International student mobility - OECD Data. Retrieved from http://data.oecd.org/students/ international-student-mobility.htm.

Pang, V. O., Stein, R., Gomez, M., Matas, A., \& Shimogori, Y. (2011). Cultural competencies: Essential elements of caring-centered multicultural education. Action in Teacher Education Journal, 33(5-6), 560-574. https://doi.org/10.1080/01626620.2011.627050.

Pope, R. L., \& Mueller, J. A. (2005). Faculty and curriculum: Examining multicultural competence and inclusion. Journal of College Student Development, 46(6), 679-688. https://doi.org/10.1353/csd.2005.0065.

Pütz, P. M., \& Mundt, N. (2018). Expanding the linguistic landscape: Linguistic diversity, multimodality and the use of space as a semiotic resource. Bristol: Multilingual Matters.

Tritschler, K. (2008). Cultural competence. Journal of Physical Education, Recreation \& Dance, 79(1), 7-8. https://doi.org/10.1080/07303084.2008.10598 107.

Trumbull, E., \& Pacheco, M. (2005). Leading with diversity: Cultural competencies for teacher preparation and professional development. Retrieved from https:// files.eric.ed.gov/fulltext/ED494221.pdf.

UNESCO. (2013). The International mobility of students in Asia and the Pacific. Retrieved from https://acasecretariat.be/newsletter/the-international-mobilityof-students-in-asia-and-the-pacific/.

Vincent, S. K., \& Torres, R. M. (2015). Multicultural competence: A case study of teachers and their student perceptions. Journal of Agricultural Education, 56(2), 64-75. https://doi.org/10.5032/ jae.2015.02064.

Y1lmaz, F. (2016). Multiculturalism and multicultural education: A case study of teacher candidates' perceptions. Cogent Education Journal, 3(1), 1172394. https://doi.org/10.1080/233118 6X.2016.1172394. 